\title{
Mode of progression after radioembolization in patients with colorectal cancer liver metastases
}

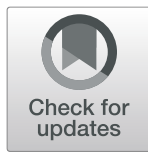

\author{
Caren van Roekel ${ }^{1 *}$ D, Jennifer M. J. Jongen², Maarten L. J. Smits' ${ }^{1}$, Sjoerd G. Elias ${ }^{3}$, Miriam Koopman", \\ Onno Kranenburg ${ }^{5}$, Inne H. M. Borel Rinkes ${ }^{2}$ and Marnix G. E. H. Lam ${ }^{1}$
}

\begin{abstract}
Background: Radioembolization is an established treatment modality in colorectal cancer patients with liverdominant disease in a salvage setting. Selection of patients who will benefit most is of vital importance. The aim of this study was to assess response (and mode of progression) at 3 months after radioembolization and the impact of baseline characteristics.

Methods: Three months after radioembolization with either yttrium-90 resin/glass or holmium-166, anatomic response, according to RECIST 1.1, was evaluated in 90 patients. Correlations between baseline characteristics and efficacy were evaluated. For more detailed analysis of progressive disease as a dismal clinical entity, distinction was made between intra- and extrahepatic progression, and between progression of existing metastases and new metastases.

Results: Forty-two patients (47\%) had extrahepatic disease (up to five $\geq 1 \mathrm{~cm}$ lung nodules, and $\leq 2 \mathrm{~cm}$ lymph nodes) at baseline. No patients showed complete response, 5 (5.5\%) patients had partial response, 16 (17.8\%) had stable disease, and 69 (76.7\%) had progressive disease. Most progressive patients $(67 / 69 ; 97 \%)$ had new metastases (intra-hepatic $N=11$, extrahepatic $N=32$; or both $N=24$ ). Significantly fewer patients had progressive disease in the group of patients presenting without extrahepatic metastases at baseline (63\% versus $93 \% ; p=0.0016)$. Median overall survival in patients with extrahepatic disease was 6.5 months, versus 10 months in patients without extrahepatic disease at baseline (hazard ratio 1.79, 95\% Cl 1.24-2.57).
\end{abstract}

Conclusions: Response at 3-month follow-up and survival were heavily influenced by new metastases. Patients with extrahepatic disease at baseline had a worse outcome compared to patients without.

Keywords: Metastatic colorectal cancer, Radioembolization, Progression, RECIST, Extrahepatic metastases

\section{Background}

Approximately $45 \%$ of colorectal cancer patients develop metastases $[1,2]$. Without treatment, the median overall survival for colorectal cancer patients with hepatic metastases (mCRC) is only 4.5 months [3]. The liver is the most common site of metastasis: up to $30 \%$ of mCRC

\footnotetext{
* Correspondence: J.vanRoekel@umcutrecht.nl

'Department of Radiology and Nuclear Medicine, University Medical Center Utrecht, University Utrecht, Heidelberglaan 100, 3584 CX Utrecht, The Netherlands

Full list of author information is available at the end of the article
}

patients develop hepatic metastases $[4,5]$. Radioembolization is a loco-regional treatment option for unresectable, systemic therapy-refractory patients with liver-only or liver-dominant disease [6, 7]. Intra-arterial administration of radioactive microspheres is proven to be safe and effective [8]. Microspheres (approximately $30 \mu \mathrm{m}$ ) are loaded with the radioactive isotope yttrium-90 $\left({ }^{90} \mathrm{Y}\right)$ or holmium-166 $\left({ }^{166} \mathrm{Ho}\right)$ and injected through a microcatheter in the hepatic artery [9]. For the treatment of metastatic colorectal cancer, ${ }^{90} \mathrm{Y}$-resin microspheres (SIR-Spheres ${ }^{\circ}$, Sirtex) are FDA- and CE-approved. ${ }^{90} \mathrm{Y}$ 
-glass microspheres (TheraSphere ${ }^{\circ}, \mathrm{BTG} /$ Boston Scientific) and ${ }^{166} \mathrm{Ho}$ microspheres (QuiremSpheres ${ }^{\circ}$, Quirem) are CE-approved for this indication, not FDA-approved. The injected microspheres embolize the microvasculature surrounding the tumor and emit high-energy betaradiation. The normal liver parenchyma is largely spared since healthy liver tissue is mainly supplied by the portal vein [10-12].

Although assessment of metabolic response has proven added benefit over anatomic response, not being hampered by, i.e., the presence of intra-tumoral necrosis and cystic changes after treatment [13, 14], response of radioembolization in $\mathrm{mCRC}$ patients is still mostly evaluated by the Response Evaluation Criteria in Solid Tumors (RECIST) [15-17]. When using these criteria, the results of most clinical studies in metastatic (liver) disease are modest, with many patients experiencing early progressive disease [18-21]. Optimized treatment planning could improve response rates [22, 23], but selecting patients who will benefit most is another vital aspect. An important criterion in patient selection is the definition of liverdominant disease. The extent of extrahepatic disease we are willing to accept is under constant debate at tumor board meetings in our center, but clear guidance is currently missing, due to the lack of data on this matter. Other prognostic factors that are known to influence response after treatment with radioembolization are (among others) KRAS status, primary tumor location, percentage tumor involvement, and pre-treatment CEA level $[19,24,25]$. These factors could possibly be used in patient selection as well.

The aim of this study was to assess the impact of baseline characteristics on changes in intra- and extrahepatic $\mathrm{mCRC}$ disease from baseline to 3 months after radioembolization, across all currently available radioembolization treatment modalities.

\section{Methods}

\section{Patient selection and study design}

A total of 129 chemorefractory, unresectable mCRC patients were treated with radioembolization at our institution between August 2009 and January 2017, predominantly as part of the HEPAR-2 (Holmium Embolization Particles for Arterial Radiotherapy II) [26], or RADAR trial (RADioembolization: Angiogenic factors and Response) [22]. The studies were conducted in accordance with the institutions' Medical Ethical Committee and informed consent was obtained from the patients treated in the HEPAR-2 and RADAR studies before inclusion. For the other patients that were treated in routine clinical practice and also included in the current retrospective analysis, the need for informed consent was waived. Inclusion criteria for all patients regarding the presence of extrahepatic metastases or the primary tumor were similar: liver-dominant disease with a maximum of five lung nodules $<1 \mathrm{~cm}$ and lymph nodes $<2 \mathrm{~cm}$. The presence of the primary tumor was not a contra-indication to treatment. Patients were included for response analysis in case CT and/or MRI scans were available at baseline and at (around) 3-month follow-up; all patients were included for survival analysis. Patients were treated with ${ }^{166} \mathrm{Ho}$-microspheres $(n=24)$ (all as part of the HEPAR 2 study), glass ${ }^{90} \mathrm{Y}$-microspheres $(n=20)$, or resin ${ }^{90} \mathrm{Y}$-microspheres $(n=46)$. Imaging was performed 3 months after treatment (i.e., whole-liver or lobar treatment in one session). In case of sequential lobar treatment, imaging was performed 3 months after the last lobar treatment.

The electronic medical records were reviewed to obtain patient characteristics. The following established independent prognostic factors in patients with mCRC were compared: age, number of previous chemotherapy lines, type of microspheres, presence of extrahepatic disease at baseline, primary tumor in situ, time since diagnosis of metastases, WHO performance status, KRAS wild type versus KRAS mutation, pre-treatment CEA level, primary tumor location (categorized as left sided (splenic flexure to rectum) or right sided (proximal to the splenic flexure)), and tumor load (percentage liver involvement, categorized as $<25 \%, 25-50 \%$, > 50\%) [21, 25, 27-33].

\section{Radioembolization}

The prescribed activity for the patients that were treated with glass ${ }^{90} \mathrm{Y}$-microspheres was calculated according to the Medical Internal Radiation Dose (MIRD) method, with a desired absorbed dose of 80-120 Gy, according to the instructions for use [34-36]. Visual and quantitative assessment of ${ }^{99 \mathrm{~m}} \mathrm{Tc}$-MAA distribution is weighted in this decision, also considering whole liver treatment in one session or sequentially. For the patients that were treated with resin ${ }^{90} \mathrm{Y}$-microspheres, the body surface area (BSA) method was used. The injected activity for ${ }^{166}$ Ho-microspheres was calculated based on the MIRD method with an aimed whole-liver absorbed dose of 60 Gy [37].

\section{Response assessments}

Two blinded readers independently performed measurements for tumor diameter on abdominal contrastenhanced CT or MRI at baseline and 3-month follow-up, using the same modality at both time points, according to RECIST version 1.1 [17]. In case no consensus was reached, a third reader gave the final call. Finally, inter-observer variability between the two raters was assessed. 
Response at 3 months was dichotomized as disease control (i.e., complete or partial response (CR or PR) and stable disease (SD)) or progressive disease (PD). For a more detailed assessment of mode of progressive disease, a further subdivision was made in four categories: growth of intrahepatic metastases, growth of extrahepatic metastases, new intrahepatic metastases, and new extrahepatic metastases. All extrahepatic metastases were taken into account, regardless of their size.

\section{Statistical analyses}

Standard descriptive statistics were used to display patient demographics and summarize response measures. Cohen's kappa was used to determine agreement. Chisquare was used to test for differences in whole body response classification. Firth's logistic regression was used to explore associations between baseline characteristics and mode of progression. This type of analysis was chosen to correct for small-sample bias [38]. The analysis for the association between extrahepatic disease at baseline and disease progression was adjusted for the following possible confounders: time from diagnosis of metastases to treatment, primary tumor in situ, KRAS mutation vs wild type, and number of lines of previous systemic treatment (one versus two or more). The analysis for the association between type of microsphere used and disease progression was adjusted for the following possible confounders: age, time from diagnosis of metastases to treatment, primary tumor in situ, KRAS mutation vs wild type, number of lines of previous systemic treatment (one versus two or more), and presence of extrahepatic disease. Univariable survival analysis by the Kaplan-Meier method was used to estimate median overall survival (OS) in all treated patients. A Cox proportional hazards model with Firth's correction was used to test for differences in survival between patients with and without extrahepatic disease at baseline. All analyses were performed using $\mathrm{R}$ version 3.6.2 for Windows. We report effect estimates with associated 95\%CIs and corresponding two-sided $p$ values.

\section{Results}

\section{Patient demographics}

Of the total cohort of 129 treated patients in our institution, 39 patients (30\%) did not have 3-month follow-up imaging available because of the following reasons: follow-up imaging in other hospitals $(n=5)$, only follow-up imaging at 1 month post-treatment $(n=21)$, only response evaluation using ${ }^{18}$ F-FDG PET (with no accompanying contrast-enhanced CT) $(n=5)$, clinical progression $(n=5)$, no follow-up imaging available $(n=$ $2)$, and RFA artifacts $(n=1)$. The remaining 90 patients had either CT $(n=67,74 \%)$ or MRI $(n=23,26 \%)$ images available at baseline and 3-month follow-up.
Median interval between baseline imaging and radioembolization was 18 days (range 1-46), between radioembolization and follow-up 91 days (range 62-165). Baseline and treatment characteristics are summarized in Table 1. ${ }^{166} \mathrm{Ho}$-microspheres, glass ${ }^{90} \mathrm{Y}$-microspheres, and resin ${ }^{90} \mathrm{Y}$-microspheres were used in 24 (27\%), 20 (22\%), and 46 patients (51\%) respectively. None of the patients received systemic treatment before $(<4$ weeks $)$, during, or after ( $<3$ months) radioembolization.

\section{Inter-observer variability}

Discordant conclusions were drawn in five patients, for whom the third rater gave the final call. The level of agreement in RECIST categories was adequate with a Cohen's kappa of 0.895 (95\% CI 0.805-0.985), $p<0.001$.

\section{Response according to RECIST 1.1}

At baseline, 42/90 (47\%) patients had extrahepatic metastases, which increased to $67 / 90$ (74\%) patients at 3month follow-up (Fig. 1).

Of the 90 patients, no patients showed CR, 5 (5.5\%) patients had PR, 16 (17.8\%) had SD, and 69 (76.7\%) had PD. According to RECIST, progressive disease can be based on growth of intrahepatic metastases, growth of extrahepatic metastases, or new metastases (either intraor extrahepatic). Growth of intrahepatic metastases was observed in 20 patients (29\%), new intrahepatic metastases in 35 patients (51\%), growth of extrahepatic metastases in 37 patients (54\%), and 56 patients (81\%) were diagnosed with new extrahepatic metastases. Most, 67/ 69 of the progressive patients (97\%), had new (intra-hepatic $N=11$, extrahepatic $N=32$; or both $N=24$ ) metastases. Progression was most often seen on multiple levels $(N=42,61 \%)$ and was only based on growth of existing metastases in 5 patients $(7 \%$, intra-hepatic $N=$ 2, extrahepatic $N=3$ ) and on only new lesions in 23 patients (69\%) (Fig. 2a). In the subgroup of progressive patients with extrahepatic disease at baseline, new extrahepatic metastases were most common, in 28/42 (67\%) patients (Fig. 2b).

There was no significant difference in response between the three types of microspheres used: compared to ${ }^{90} \mathrm{Y}$ resin microspheres, the odds ratios for progressive disease with ${ }^{90} \mathrm{Y}$ glass and ${ }^{166}$ Ho were 1.11 (95\%CI $0.32-$ 4.53 ) and 0.67 (95\%CI 0.22-2.14), respectively (Table 2).

\section{Correlations between baseline characteristics and response}

The association between several baseline characteristics and response was assessed (Table 2). Presence of extrahepatic disease was the most significant risk factor for progressive disease, with an OR of 7.8 (95\% CI 2.3735.53) for patients with extrahepatic disease at baseline versus patients without extrahepatic disease at baseline 
Table 1 Baseline and treatment characteristics

\begin{tabular}{|c|c|c|c|c|c|c|}
\hline \multirow[t]{2}{*}{ Characteristic } & \multicolumn{4}{|c|}{$N(\%)$ or median with range } & \multirow[b]{2}{*}{$\begin{array}{l}\text { Extrahepatic } \\
\text { disease at baseline }\end{array}$} & \multirow[b]{2}{*}{ Total } \\
\hline & ${ }^{90} Y$-resin & ${ }^{90} \mathrm{Y}$-glass & ${ }^{166} \mathrm{Ho}$ & $\begin{array}{l}\text { No extrahepatic } \\
\text { disease }\end{array}$ & & \\
\hline$N$ & $46(51)$ & $20(22)$ & $24(27)$ & $48(53)$ & $42(47)$ & $90(100)$ \\
\hline Age (years) & $65(35-84)$ & $67(45-78)$ & $66(40-84)$ & $66(34-84)$ & $66(40-84)$ & $66(35-84)$ \\
\hline \multicolumn{7}{|l|}{ Gender } \\
\hline Male & $33(72)$ & $15(75)$ & $17(63)$ & $34(71)$ & $31(74)$ & $65(72)$ \\
\hline Female & $13(28)$ & $5(25)$ & $7(37)$ & $14(29)$ & $11(26)$ & $25(28)$ \\
\hline \multicolumn{7}{|l|}{ WHO performance status } \\
\hline 0 & $24(52)$ & $15(75)$ & $19(79)$ & $29(60)$ & $29(69)$ & $58(64)$ \\
\hline 1 & $19(41)$ & $5(25)$ & $5(21)$ & $18(38)$ & $11(26)$ & $29(32)$ \\
\hline 2 & $3(7)$ & $0(0)$ & $0(0)$ & $1(2)$ & $2(5)$ & $3(4)$ \\
\hline \multicolumn{7}{|l|}{ Previous chemotherapy lines } \\
\hline 0 & $1(2)$ & $0(0)$ & $0(0)$ & $1(2)$ & $0(0)$ & $1(1)$ \\
\hline 1 & $13(28)$ & $9(45)$ & $11(46)$ & $18(38)$ & $15(36)$ & $33(37)$ \\
\hline 2 & $21(46)$ & $8(40)$ & $11(46)$ & $21(44)$ & $9(21)$ & $40(44)$ \\
\hline 3 & $11(24)$ & $3(15)$ & $2(8)$ & $8(17)$ & $8(19)$ & $16(18)$ \\
\hline Bevacizumab & $29(63)$ & $13(65)$ & $13(54)$ & $32(67)$ & $23(55)$ & $55(61)$ \\
\hline Capecitabine & $42(91)$ & $18(90)$ & $20(83)$ & $41(85)$ & 39 (93) & $80(89)$ \\
\hline Cetuximab & $2(4)$ & $0(0)$ & $1(4)$ & $1(2)$ & $2(5)$ & $3(4)$ \\
\hline Cisplatin & $1(2)$ & $0(0)$ & $0(0)$ & $1(2)$ & $0(0)$ & $1(1)$ \\
\hline Erlotinib & $0(0)$ & $0(0)$ & $1(4)$ & $0(0)$ & $1(2)$ & $1(1)$ \\
\hline Irinotecan & $26(57)$ & $9(45)$ & $10(42)$ & $23(48)$ & $22(52)$ & $45(50)$ \\
\hline Oxaliplatin & $40(87)$ & $17(85)$ & $23(96)$ & $41(85)$ & 39 (93) & $80(89)$ \\
\hline Paclitaxel & $0(0)$ & $0(0)$ & $1(4)$ & $0(0)$ & $1(1)$ & $1(1)$ \\
\hline Panitumumab & $8(17)$ & $4(20)$ & $3(13)$ & $9(19)$ & $6(14)$ & $15(17)$ \\
\hline $5-\mathrm{FU}$ & $7(15)$ & $3(15)$ & $5(21)$ & $7(15)$ & $8(19)$ & $15(17)$ \\
\hline \multicolumn{7}{|l|}{ Previous locoregional treatment } \\
\hline Yes & $17(37)$ & $7(35)$ & $6(25)$ & $17(35)$ & $13(31)$ & $30(33)$ \\
\hline No & $29(63)$ & $13(65)$ & $18(75)$ & $31(65)$ & $29(69)$ & $60(67)$ \\
\hline \multicolumn{7}{|l|}{ Metastasis pattern } \\
\hline Synchronous & $31(67)$ & $15(75)$ & $15(63)$ & $27(56)$ & $34(81)$ & $61(68)$ \\
\hline Metachronous & $15(33)$ & $5(25)$ & $9(37)$ & $21(44)$ & $8(19)$ & $29(32)$ \\
\hline Time since diagnosis (months) & $25(3-97)$ & $24(11-110)$ & $26(6-92)$ & $26(3-110)$ & $21(5-92)$ & $25(3-110)$ \\
\hline $\begin{array}{l}\text { Time since diagnosis of } \\
\text { metastatic disease (months) }\end{array}$ & $17(3-72)$ & $23(2-50)$ & $18(2-92)$ & $17(2-54)$ & $21(5-92)$ & $19(2-92)$ \\
\hline \multicolumn{7}{|l|}{ KRAS status } \\
\hline Wild-type & $16(35)$ & $8(40)$ & $9(37)$ & $21(44)$ & $12(29)$ & $33(37)$ \\
\hline Mutation & $11(24)$ & $3(15)$ & $6(26)$ & $7(15)$ & $13(31)$ & $20(22)$ \\
\hline Unknown & $19(41)$ & $9(45)$ & $9(37)$ & $10(21)$ & $17(40)$ & $37(41)$ \\
\hline CEA level & $72(3-2700)$ & $68(3-640)$ & $100(2-6000)$ & $61(2-2700)$ & $115(3-6000)$ & $88(2-6000)$ \\
\hline Unknown & $12(26)$ & $4(20)$ & $1(4)$ & $7(15)$ & $10(24)$ & $17(19)$ \\
\hline \multicolumn{7}{|l|}{ Primary tumor in situ } \\
\hline Yes & $1(2)$ & $4(20)$ & $2(8)$ & $2(4)$ & $5(12)$ & 7 (8) \\
\hline No & $45(98)$ & $16(80)$ & $22(92)$ & $46(96)$ & $37(88)$ & $83(92)$ \\
\hline
\end{tabular}


Table 1 Baseline and treatment characteristics (Continued)

\begin{tabular}{|c|c|c|c|c|c|c|}
\hline \multirow[t]{2}{*}{ Characteristic } & \multicolumn{4}{|c|}{$N(\%)$ or median with range } & \multirow[b]{2}{*}{$\begin{array}{l}\text { Extrahepatic } \\
\text { disease at baseline }\end{array}$} & \multirow[b]{2}{*}{ Total } \\
\hline & ${ }^{90} Y$-resin & ${ }^{90} Y$-glass & ${ }^{166} \mathrm{Ho}$ & $\begin{array}{l}\text { No extrahepatic } \\
\text { disease }\end{array}$ & & \\
\hline \multicolumn{7}{|l|}{$\begin{array}{l}\text { Extrahepatic disease } \\
\text { (all metastases) }\end{array}$} \\
\hline None & $27(59)$ & $9(45)$ & $10(42)$ & $48(100)$ & $0(0)$ & $48(53)$ \\
\hline Lymph node metastases & $12(26)$ & $8(40)$ & $7(29)$ & - & $25(60)$ & $25(28)$ \\
\hline Lung metastases & $8(17)$ & $2(10)$ & $7(29)$ & - & $17(40)$ & $17(19)$ \\
\hline Abdominal wall metastases & $1(2)$ & $0(0)$ & $0(0)$ & - & $1(2)$ & $1(1)$ \\
\hline Spleen metastases & $0(0)$ & $0(0)$ & $2(8)$ & - & $1(2)$ & $1(1)$ \\
\hline Adrenal gland metastases & $0(0)$ & $2(10)$ & $0(0)$ & - & $2(5)$ & $2(2)$ \\
\hline Peritoneal metastases & $1(2)$ & $0(0)$ & $2(8)$ & - & $3(7)$ & $3(3)$ \\
\hline \multicolumn{7}{|l|}{ Type of radioembolization } \\
\hline Whole-liver & $41(89)$ & $12(60)$ & $20(83)$ & $38(79)$ & $35(83)$ & $73(81)$ \\
\hline Lobar & $5(11)$ & $8(40)$ & $4(17)$ & $10(21)$ & $7(17)$ & $17(19)$ \\
\hline Injected activity (MBq) & $1526(636-2320)$ & 2037 (711-6277) & $6565(2213-11,627)$ & $1882(636-11,164)$ & $1992(680-11,627)$ & Not applicable \\
\hline Lungshunt (\%) & $5(0.1-17)$ & $2.3(1-26)$ & $4.6(0.3-16)$ & $4.5(0.1-17)$ & $3.4(0.8-26)$ & $4(0.1-26)$ \\
\hline
\end{tabular}

This table shows the baseline characteristics for the 90 included patients

\section{Sites of extrahepatic disease}

A Baseline

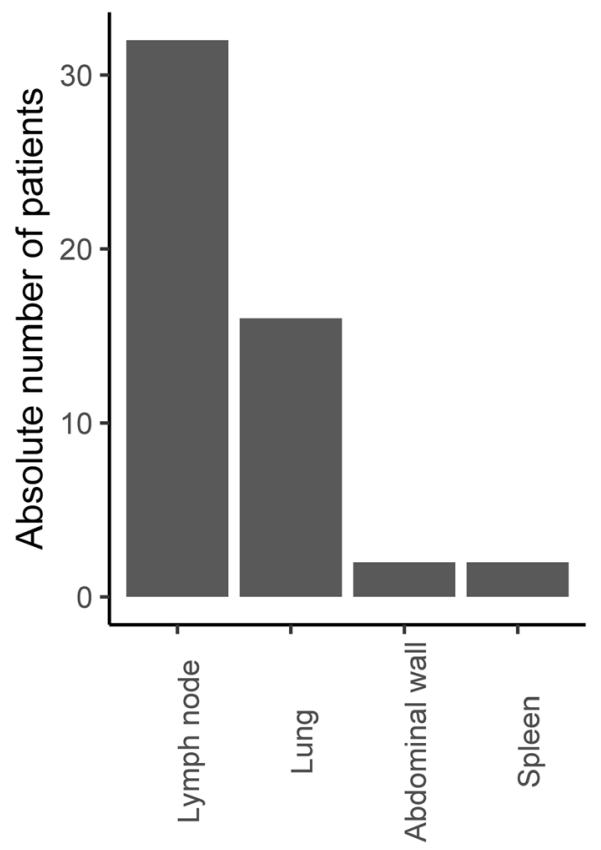

B Three months follow-up

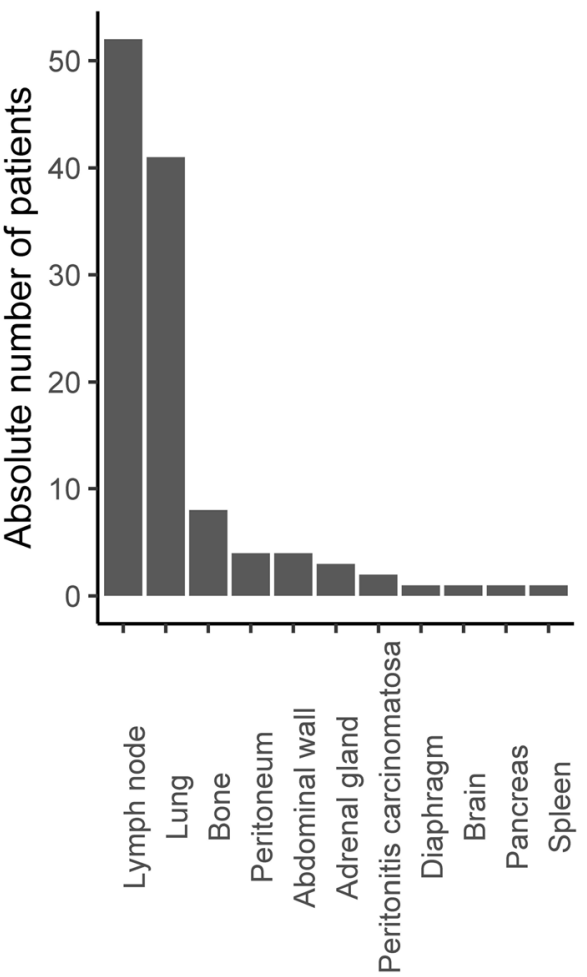

Fig. 1 Site of extrahepatic metastases at baseline and at 3-month follow-up. a Type and number of affected organs in patients with extrahepatic metastases at baseline. Bars depict absolute number of patients. In total, 50 affected organs in 42 patients. b As in $\mathbf{a}$, for 3-month follow-up. In total, 119 affected organs in 67 patients. Lymph nodes and lung are most affected at baseline and 3-month follow-up 


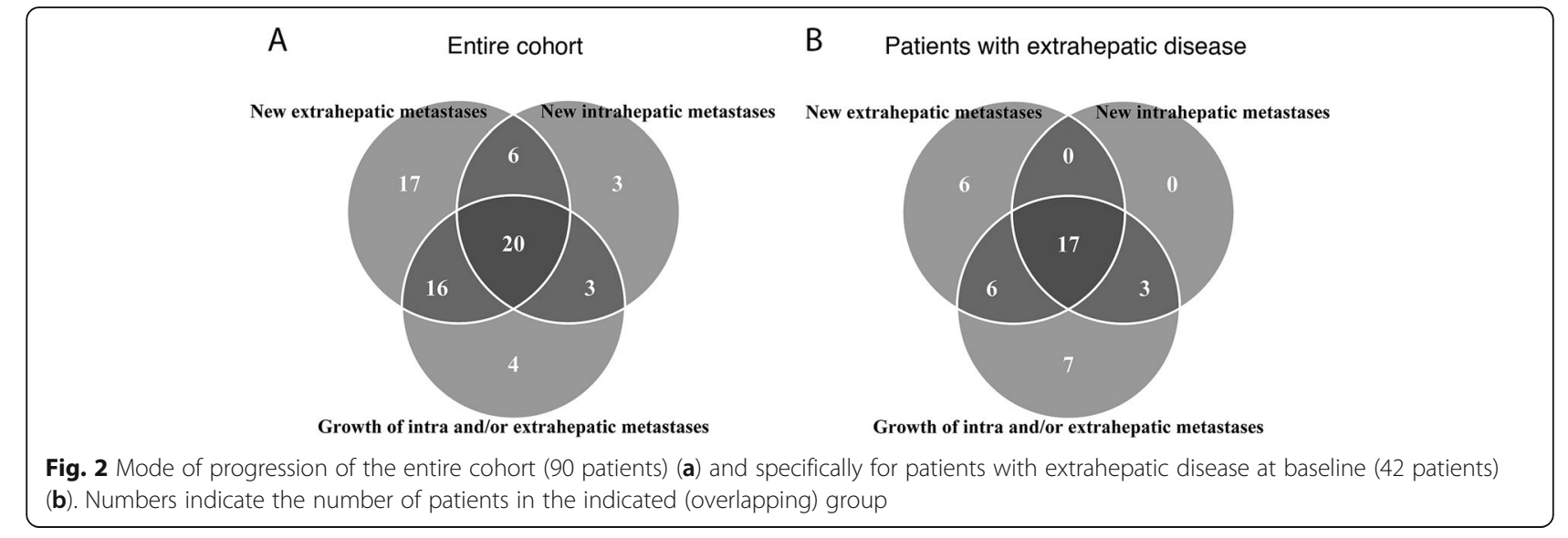

B Patients with extrahepatic disease

(Fig. 3). Extrahepatic metastases at baseline increased the risk of progressive disease for all modes of progression, mainly for new extrahepatic metastases $(\mathrm{OR}=3.06$, 95\% CI 1.28-7.72). Time since diagnosis of metastases was a significant risk factor for progressive disease as well, with an OR of 1.06 for every month increase in time (95\%CI 1.01-1.11). Primary tumor location showed a strong trend, with an OR of 3.88 (95\%CI 1.00-25.75) for patients with right-sided primary tumors versus patients with left-sided primary tumors. There was no significant difference between types of microspheres used.

The difference in response evaluation was compared for patients with or without extrahepatic metastases at baseline. Of the group $(n=42,47 \%)$ presenting with extrahepatic metastases at baseline, 93\% was diagnosed with PD at 3-month follow-up. Significantly fewer patients $(63 \%)$ were diagnosed with progressive disease in the group of patients $(n=48,53 \%)$ presenting without extrahepatic metastases at baseline $(p=0.0017)$ (Table 3).

\section{Prognostic value of extrahepatic disease at baseline based on overall survival (OS)}

Median OS for the 90 included patients was 10 months (95\% CI 9-14 months). Presence of extrahepatic metastases at baseline showed a difference in median OS estimates with 10 months (95\% CI 7-14) for patients with and 12 months (95\% CI 9-19) for patients without extrahepatic metastases at baseline (hazard ratio (HR) 1.68, 95\%CI (1.09-2.59), $p=0.019$ ) (Fig. 4).

\section{Discussion}

This study shows that a large proportion of end-stage mCRC patients have progressive disease after radioembolization due to the development of new metastases, and to a lesser extent due to the growth of existing metastases. The presence of extrahepatic disease at baseline significantly increases the chance of early progressive disease at 3 months, especially the development of new metastases. Moreover, patients with extrahepatic metastases at baseline had a significantly worse overall survival.

At baseline, $48 \%$ of our study population was diagnosed with extrahepatic metastases. This is in line with other studies in which $35-77 \%$ of the included patients had extrahepatic metastases at baseline [18-20, 39-44]. We found a difference in median OS with and without the presence of extrahepatic metastases at baseline, respectively 7 versus 10 months $(p=0.0018)$. Several other studies with a comparable patient population also found that extrahepatic disease was a predictor of survival after radioembolization [24, 45-49]. Other known prognostic factors are tumor load, baseline CEA level, and location (left- versus right-sidedness) of the primary tumor [24, $49,50]$. In our study, only location of the primary tumor showed a clear trend for significance, with the odds ratio for progressive disease being 3.88 (95\%CI 1.00-25.75) for patients with a right-sided primary tumor versus patients with a left-sided primary tumor.

Genetics and biomarkers are more and more recognized as prognostic factors. We investigated the possible role of CEA, since this was associated with poorer survival after radioembolization in multiple studies [19, 24, 51]. However, just as in the study of Sofocleus et al., in our study, no significant correlation between pretreatment CEA level and disease progression was found [19]. Patients with KRAS mutation generally have a worse prognosis after radioembolization than patients with KRAS wild-type status [19, 24, 25, 52]. In our study, although not significant, the odds ratios for all types of progressive disease showed a clear trend for a worse prognosis for patients with KRAS mutation versus patients with KRAS wild type (Table 2).

In The Netherlands, indications for radioembolization include liver-dominant, irresectable, systemic therapyrefractory disease. Patients with significant extrahepatic metastases are not considered eligible, but patients with stable, limited extrahepatic disease (defined by the Dutch 


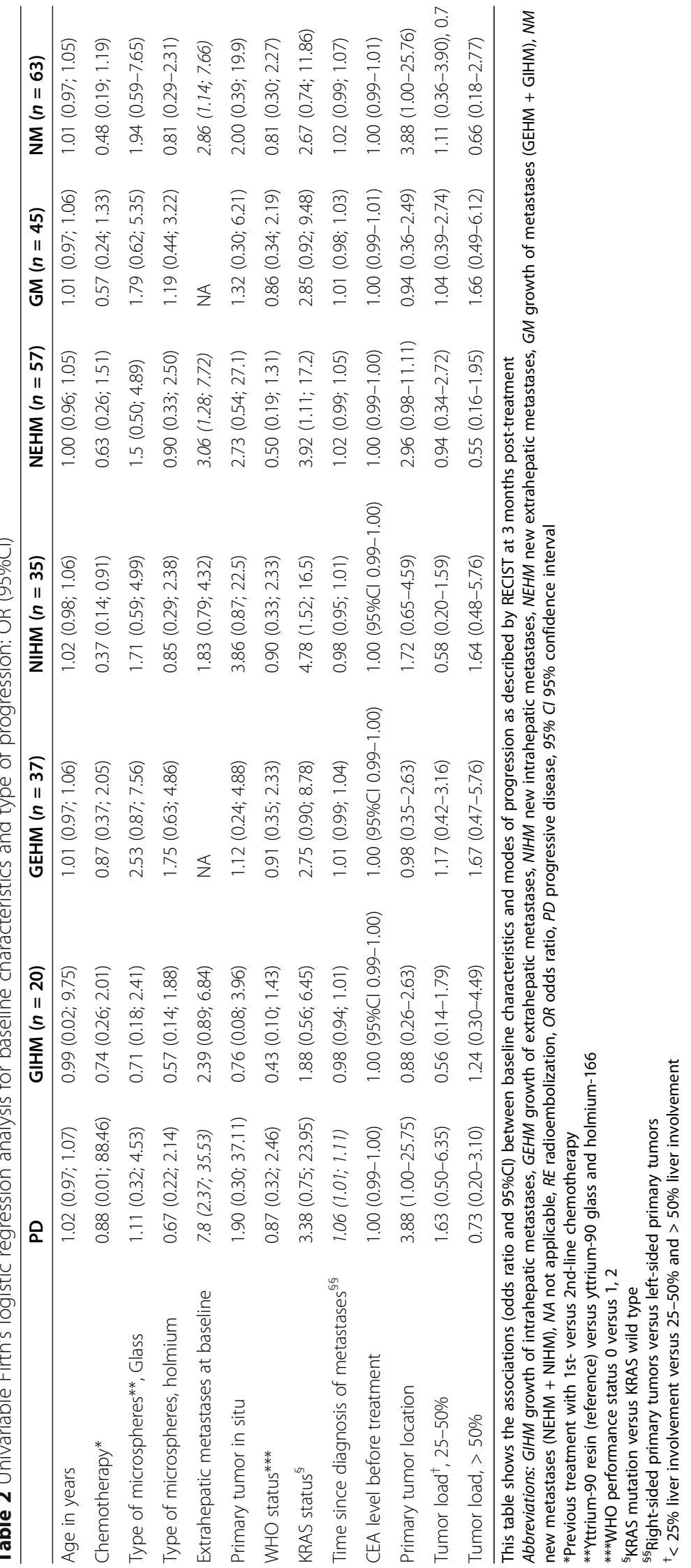




\section{Influence of baseline characteristics on response}

$\begin{array}{lrr}\text { Baseline factor } & \text { OR } & \mathbf{9 5 \%} \mathbf{C l} \\ \text { Age } & 1.02 & 0.97-1.07 \\ \text { Chemotherapy } & 0.88 & 0.01-88.46 \\ \text { Glass microspheres } & 1.11 & 0.32-4.53 \\ \text { Holmium microspheres } & 0.67 & 0.22-2.14 \\ \text { Extrahepatic metastases } & 7.80 & 2.37-35.53 \\ \text { Primary tumor } & 1.90 & 0.30-37.11 \\ \text { WHO status } & 0.87 & 0.32-2.46 \\ \text { KRAS } & 3.38 & 0.75-23.95 \\ \text { Time since metastasis } & 1.06 & 1.01-1.11 \\ \text { CEA level } & 1.00 & 0.99-1.00 \\ \text { Primary tumor location } & 3.88 & 1.00-25.75 \\ \text { Tumorload 25-50\% } & 1.63 & 0.50-6.35 \\ \text { Tumorload }>50 \% & 0.73 & 0.20-3.10\end{array}$

Fig. 3 Forest plot of the influence of baseline characteristics on response (progression versus no progression according to RECIST 1.1), based on univariable analyses

National Healthcare Institute as a maximum of 5 lung nodules $<1 \mathrm{~cm}$ and lymph nodes $<2 \mathrm{~cm}$ ) are eligible [53]. This criterion was also used in the patients in this study. The SIRFLOX, FOXFIRE, and FOXFIRE-Global (studying the added value of radioembolization to chemotherapy in first-line mCRC patients) used similar inclusion criteria with respect to extrahepatic disease [54]. In these studies, no difference in OS or overall progression-free survival (PFS) was observed [55]. One may argue that the large percentage of patients with extrahepatic disease in these studies (i.e., 36\%) clouded the potential clinical benefit of radioembolization in a more stringent selected subset. In a subgroup of patients with right-sided primary tumors, the presence of extrahepatic metastases at baseline indeed proved to be a negative prognostic factor for OS, with a HR of 1.351 (95\%CI 0.96-1.91) [50]. Importantly, these studies were performed in first-line refractory disease. This limits comparison with our study in a more advanced-stage population.

Objective response (CR or PR) at 3 months after treatment was obtained in only $6 \%$ of our patients. This is in line with other studies in salvage mCRC patients, with reported response ranges of $6-24 \%$ [24, 56, 57]. Median OS in our study was 10 months, which is also in line with other studies in a comparable patient population $[22,24,58]$.

A reason for the modest treatment results in our study might be the dosimetric models that were used: the BSA and MIRD methods. These methods can lead to underdosing $[59,60]$. A personalized treatment approach, as was used in the DOSISPHERE study in HCC patients, could have led to a much higher response rate [61]. The results of earlier studies on the dose-response relations in $\mathrm{mCRC}$ patients treated with ${ }^{90} \mathrm{Y}$-resin or ${ }^{166} \mathrm{Ho}$ prove this point: a significant dose-response relationship was found in both studies [22, 62]. Implementing the results of these studies in future patients, using an individualized treatment approach, likely will lead to a higher treatment accuracy.

In our study, response was evaluated using the anatomic criteria as defined by the RECIST guidelines. However, this can be hampered by the presence of necrosis, hemorrhage, and cystic changes [63]. Response assessment based on changes in functional metrics as determined on $\left[{ }^{18} \mathrm{~F}\right]$-FDG PET/CT would be a better 
Table 3 RECIST 1.1 response classification at 3 months post-treatment

\begin{tabular}{|c|c|c|c|}
\hline \multirow[t]{4}{*}{ Total } & \multirow[t]{2}{*}{ No extrahepatic metastases at baseline } & & $48(53 \%)$ \\
\hline & & $\begin{array}{l}\text { Complete response } \\
\text { Partial response } \\
\text { Stable disease } \\
\text { Progressive disease }\end{array}$ & $\begin{array}{l}0(0 \%) \\
5(10 \%) \\
13(27 \%) \\
30(63 \%)\end{array}$ \\
\hline & \multirow[t]{2}{*}{ Extrahepatic metastases at baseline } & & $42(47 \%)$ \\
\hline & & $\begin{array}{l}\text { Complete response } \\
\text { Partial response } \\
\text { Stable disease } \\
\text { Progressive disease }\end{array}$ & $\begin{array}{l}0(0 \%) \\
0(0 \%) \\
3(7 \%) \\
39(93 \%)^{*}\end{array}$ \\
\hline \multirow[t]{4}{*}{ Yttrium-90 Resin } & \multirow[t]{2}{*}{ No extrahepatic metastases at baseline } & & $28(61 \%)$ \\
\hline & & $\begin{array}{l}\text { Complete response } \\
\text { Partial response } \\
\text { Stable disease } \\
\text { Progressive disease }\end{array}$ & $\begin{array}{l}0(0 \%) \\
1(4 \%) \\
7(25 \%) \\
20(71 \%)\end{array}$ \\
\hline & \multirow[t]{2}{*}{ Extrahepatic metastases at baseline } & & $18(39 \%)$ \\
\hline & & $\begin{array}{l}\text { Complete response } \\
\text { Partial response } \\
\text { Stable disease } \\
\text { Progressive disease }\end{array}$ & $\begin{array}{l}0(0 \%) \\
0(0 \%) \\
2(11 \%) \\
16(89 \%)\end{array}$ \\
\hline \multirow[t]{4}{*}{ Yttrium-90 Glass } & \multirow[t]{2}{*}{ No extrahepatic metastases at baseline } & & $9(45 \%)$ \\
\hline & & $\begin{array}{l}\text { Complete response } \\
\text { Partial response } \\
\text { Stable disease } \\
\text { Progressive disease }\end{array}$ & $\begin{array}{l}0(0 \%) \\
2(22 \%) \\
2(22 \%) \\
5(56 \%)\end{array}$ \\
\hline & \multirow[t]{2}{*}{ Extrahepatic metastases at baseline } & & $11(55 \%)$ \\
\hline & & $\begin{array}{l}\text { Complete response } \\
\text { Partial response } \\
\text { Stable disease } \\
\text { Progressive disease }\end{array}$ & $\begin{array}{l}0(0 \%) \\
0(0 \%) \\
0(0 \%) \\
11(100 \%)\end{array}$ \\
\hline \multirow[t]{4}{*}{ Holmium-166 } & \multirow[t]{2}{*}{ No extrahepatic metastases at baseline } & & $11(46 \%)$ \\
\hline & & $\begin{array}{l}\text { Complete response } \\
\text { Partial response } \\
\text { Stable disease } \\
\text { Progressive disease }\end{array}$ & $\begin{array}{l}0(0 \%) \\
2(18 \%) \\
4(36 \%) \\
5(46 \%)\end{array}$ \\
\hline & \multirow[t]{2}{*}{ Extrahepatic metastases at baseline } & & $13(54 \%)$ \\
\hline & & $\begin{array}{l}\text { Complete response } \\
\text { Partial response } \\
\text { Stable disease } \\
\text { Progressive disease }\end{array}$ & $\begin{array}{l}0(0 \%) \\
0(0 \%) \\
1(8 \%) \\
12(92 \%)\end{array}$ \\
\hline
\end{tabular}

This table shows a comparison of RECIST 1.1 response classification at 3 months post-treatment for patients with or without extrahepatic metastases at baseline. Numbers represent number of patients (\% of total/subcategory)

*Marks significant difference between groups; $p<0.05$

evaluation method, especially since several studies found that these are related with overall survival $[13,22,64$, 65]. Unfortunately, not all patients in our study underwent baseline and post-treatment imaging by $\left[{ }^{18} \mathrm{~F}\right]$-FDG $\mathrm{PET} / \mathrm{CT}$.

The added value of the present study to the existing knowledge on radioembolization in mCRC patients is the fact that the development of new metastases is the primary cause for progressive disease after treatment. Furthermore, the study shows that the development of new lesions, as well as progressive disease in general, is more common in patients with extrahepatic disease at baseline.
The current study also has several limitations. First of all, the sample size was small. Secondly, the retrospective setting was prone to selection bias. Since radioembolization was used in a salvage setting, outcome was likely muddled by the effect of other, previous therapies (Table 1). However, since patients were selected for radioembolization based on their chemo-resistant tumors, the contribution of this variation in our patient population on the outcome of our study was considered minimal. Third, all patients were discussed in a multidisciplinary tumor board before treatment. Based on available imaging, the primary tumor was assessed for stability and the extrahepatic disease load was assessed for extent, 


\section{Survival in patients with or without extrahepatic disease}

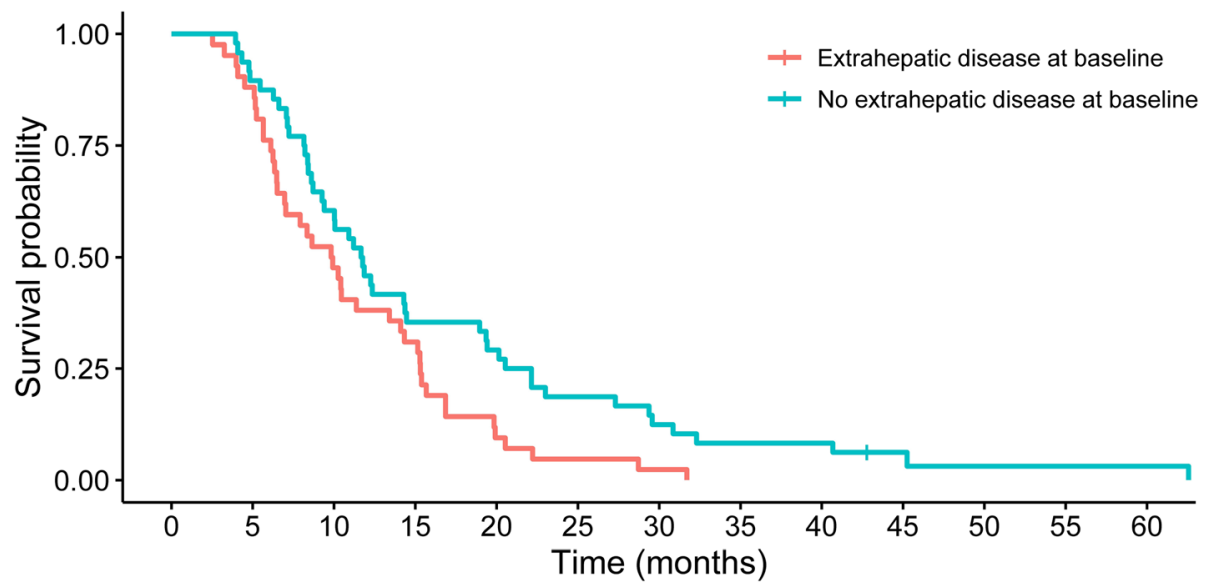

Number at risk

\begin{tabular}{rcccccccccccc}
42 & 37 & 20 & 13 & 4 & 2 & 1 & 0 & 0 & 0 & 0 & 0 & 0 \\
48 & 43 & 29 & 17 & 14 & 9 & 6 & 4 & 4 & 2 & 1 & 1 & 1 \\
\hline 0 & 5 & 10 & 15 & 20 & 25 & 30 & 35 & 40 & 45 & 50 & 55 & 60
\end{tabular}

Fig. 4 Kaplan-Meier survival curve stratified for extrahepatic metastases at baseline

however, not for stability. Also, although radioembolization is nowadays often performed in a lobar approach, a large fraction of patients that we studied received wholeliver treatment. Whole-liver treatment was in large part dictated by study protocols. Furthermore, three types of microspheres were used in our dataset. The differences with regard to the embolic nature of the treatment, the specific activity of the microspheres, the administered activities, and the absorbed doses may have influenced the incidence of early progressive disease, and potentially also the mode of progression, although our analyses did not show a significant difference between microsphere types. Last, KRAS status was unknown in $42 \%$ of the patients, making the number of patients for the subgroup analyses for KRAS rather small.

Proper selection of patients seems fundamental for the cost-effectiveness of radioembolization treatment. Future prospective studies in the salvage setting should therefore be conservative with regard to the acceptance of extrahepatic disease. Accurate baseline imaging, including FDG-PET, may aid patient selection [66]. This will avoid futile treatments and unnecessary toxicity. However, the effect of radioembolization in patients with extrahepatic disease should be evaluated in prospective studies comparing radioembolization with best supportive care, before a firm statement can be made about the exclusion of patients with extrahepatic disease from treatment. Also, considering the development of new lesions as the major cause of progressive disease, a study in the third line, comparing TAS-102 or regorafenib with and without radioembolization, would be interesting. The study of Hendlisz et al. showed that radioembolization combined with chemotherapy was safe and effective [58]. Based on the results of this study, chemotherapy in addition to radioembolization was therefore recommended in the refractory setting.

Proper selection and individualized dosimetry-based treatment planning should ultimately lead to improved treatment accuracy in mCRC patients.

\section{Conclusions}

In conclusion, response at 3-month follow-up and survival were heavily influenced by new intra- and extrahepatic metastases. Patients with extrahepatic disease at baseline had a worse outcome compared to patients without extrahepatic disease at baseline. Based on the results of this observational, retrospective study, extrahepatic disease may be considered a contraindication for treatment with radioembolization.

\footnotetext{
Abbreviations

${ }^{90}$ Y: Yttrium-90; ${ }^{166} \mathrm{Ho}$ : Holmium-166; BSA: Body surface area; CR: Complete response; CRC: Colorectal cancer; $\mathrm{mCRC}$ : Colorectal cancer metastases; MIRD: Medical Internal Radiation Dose; OS: Overall survival;

HCC: Hepatocellular carcinoma; HEPAR-2: Holmium Embolization Particles for Arterial Radiotherapy II; HR: Hazard ratio; PD: Progressive disease;

PFS: Progression-free survival; PR: Partial response; RADA

R: RADioembolization: Angiogenic factors and Response; RECIST: Response evaluation criteria in solid tumors; SD: Stable disease
}

\section{Acknowledgements}

The authors thank Christiaan van Kesteren for his help in preparing the figures. 


\section{Authors' contributions}

CR was involved in conception and design of the study, performed the analyses, wrote the manuscript, and did the response assessments. JJ was involved in the design of the study, helped write the manuscript, and also did the response assessments. MS was involved in the design of the study, helped write the manuscript, and was involved in a critical revision before it was decided to publish the article. SE was involved in the design of the study, helped perform the analyses, and was involved in a critical revision before it was decided to publish the article. MK was involved in the design of the study and was involved in a critical revision before it was decided to publish the article. OK was involved in the design of the study and was involved in a critical revision before it was decided to publish the article. IBR was involved in the design of the study and was involved in a critical revision before it was decided to publish the article. ML was involved in conception and design of the study, helped write the manuscript, and was involved in a critical revision before it was decided to publish this article. He was also consulted in consensus meetings regarding response assessment. The authors read and approved the final manuscript.

\section{Funding}

This study was supported by the Dutch Cancer Society (grant no. UU2013 -5865 for J.J.). The Department of Radiology and Nuclear Medicine of the University Medical Center Utrecht has received royalties and research support from Quirem Medical. The HEPAR I and II studies were sponsored by a grant from the Dutch Cancer Society and the Technology Foundation STW.

\section{Availability of data and materials}

The datasets used and/or analyzed during the current study are available from the corresponding author on reasonable request.

\section{Ethics approval and consent to participate}

All procedures performed in this study were in accordance with the ethical standards of the institutional and national research committee and with the 1964 Helsinki Declaration and its later amendments or comparable ethical standards.

\section{Consent for publication}

The institutions' Medical Ethical Committee provided a waiver for informed consent for this retrospective analysis.

\section{Competing interests}

M.G.E.H. Lam is a consultant for BTG and Terumo. M.L.J. Smits has served as a speaker for BTG, Sirtex, and Terumo. The other authors have no competing interests.

\section{Author details}

'Department of Radiology and Nuclear Medicine, University Medical Center Utrecht, University Utrecht, Heidelberglaan 100, 3584 CX Utrecht, The Netherlands. ${ }^{2}$ Department of Surgical Oncology, Endocrine and GI Surgery, Cancer Center, University Medical Center Utrecht, University Utrecht, Utrecht, The Netherlands. ${ }^{3}$ Julius Center for Health Sciences and Primary Care, University Medical Center Utrecht, University Utrecht, Utrecht, The Netherlands. ${ }^{4}$ Department of Medical Oncology, Cancer Center, University Medical Center Utrecht, University Utrecht, Utrecht, The Netherlands. ${ }^{5}$ Division of Biomedical Genetics, University Medical Center Utrecht, University Utrecht, Utrecht, The Netherlands.

\section{Received: 3 June 2020 Accepted: 10 September 2020} Published online: 22 September 2020

\section{References}

1. Norstein J, Silen W. Natural history of liver metastases from colorectal carcinoma. Journal of gastrointestinal surgery : official journal of the Society for Surgery of the Alimentary Tract. 1997;1 (5):398-407.

2. Ruers T, Bleichrodt RP. Treatment of liver metastases, an update on the possibilities and results. European journal of cancer (Oxford, England: 1990). 2002;38(7):1023-33.

3. Bengtsson G, Carlson G, Hafstrom L, Jonsson PE. Natural history of patients with untreated liver metastases from colorectal cancer. Am J Surg. 1981;141: 586-9.
4. Manfredi S, Lepage C, Hatem C, Coatmeur O, Faivre J, Bouvier AM. Epidemiology and management of liver metastases from colorectal cancer. Ann Surg. 2006;244(2):254-9. https://doi.org/10.1097/01.sla. 0000217629.94941.cf.

5. Engstrand J, Nilsson H, Stromberg C, Jonas E, Freedman J. Colorectal cancer liver metastases - a population-based study on incidence, management and survival. BMC Cancer. 2018;18(1):78. https://doi.org/10. 1186/s12885-017-3925-X.

6. Benson AB, Venook AP, Al-Hawary MM, Cederquist L, Chen YJ, Ciombor KK, Cohen S, Cooper HS, Deming D, Engstrom PF, Garrido-Laguna I, Grem JL, Grothey A, Hochster HS, Hoffe S, Hunt S, Kamel A, Kirilcuk N, Krishnamurthi S, Messersmith WA, Meyerhardt J, Miller ED, Mulcahy MF, Murphy JD, Nurkin S, Saltz L, Sharma S, Shibata D, Skibber JM, Sofocleous CT, Stoffel EM, Stotsky-Himelfarb E, Willett CG, Wuthrick E, Gregory KM, Freedman-Cass DA. NCCN guidelines insights: colon cancer, Version 2.2018. Journal of the National Comprehensive Cancer Network : JNCCN. 2018;16(4):359-69. https://doi.org/10.6004/jnccn.2018.0021.

7. Van Cutsem E, Cervantes A, Adam R, Sobrero A, Van Krieken JH, Aderka D, Aranda Aguilar E, Bardelli A, Benson A, Bodoky G, Ciardiello F, D'Hoore A, Diaz-Rubio E, Douillard JY, Ducreux M, Falcone A, Grothey A, Gruenberger T, Haustermans $\mathrm{K}$, Heinemann V, Hoff P, Kohne CH, Labianca R, Laurent-Puig P, Ma B, Maughan T, Muro K, Normanno N, Osterlund P, Oyen WJ, Papamichael D, Pentheroudakis G, Pfeiffer P, Price TJ, Punt C, Ricke J, Roth A, Salazar R, Scheithauer W, Schmoll HJ, Tabernero J, Taieb J, Tejpar S, Wasan H, Yoshino T, Zaanan A, Arnold D. ESMO consensus guidelines for the management of patients with metastatic colorectal cancer. Annals of oncology : official journal of the European Society for Medical Oncology. 2016;27(8):1386-422. https://doi.org/10.1093/annonc/mdw235.

8. Murthy R, Habbu A, Salem R. Trans-arterial hepatic radioembolisation of yttrium-90 microspheres. Biomedical imaging and intervention journal. 2006;2(3):e43. https://doi.org/10.2349/biij.2.3.e43.

9. Smits ML, Prince JF, Rosenbaum CE, van den Hoven AF, Nijsen JF, Zonnenberg BA, Seinstra BA, Lam MG, van den Bosch MA. Intra-arterial radioembolization of breast cancer liver metastases: a structured review. Eur J Pharmacol. 2013;709(1-3):37-42. https://doi.org/10.1016/j.ejphar. 2012.11.067.

10. Bierman HR, Byron RL Jr, Kelley KH, Grady A. Studies on the blood supply of tumors in man. III. Vascular patterns of the liver by hepatic arteriography in vivo. J Natl Cancer Inst. 1951;12(1):107-31.

11. Breedis C, Young $G$. The blood supply of neoplasms in the liver. Am J Pathol. 1954;30(5):969-77.

12. Lien WM, Ackerman NB. The blood supply of experimental liver metastases. II. A microcirculatory study of the normal and tumor vessels of the liver with the use of perfused silicone rubber. Surgery. 1970;68(2):334-40.

13. Bastiaannet $\mathrm{R}$, Lodge MA, de Jong $\mathrm{H}$, Lam $\mathrm{M}$. The unique role of fluorodeoxyglucose-PET in radioembolization. PET Clin. 2019;14(4):447-57. https://doi.org/10.1016/j.cpet.2019.06.002.

14. Sager S, Akgun E, Uslu-Besli L, Asa S, Akovali B, Sahin O, Yeyin N, Demir M, Abuqbeitah M, Gulsen F, Sayman H, Sonmezoglu K. Comparison of PERCIST and RECIST criteria for evaluation of therapy response after yttrium-90 microsphere therapy in patients with hepatocellular carcinoma and those with metastatic colorectal carcinoma. Nucl Med Commun. 2019;40(5):461-8. https://doi.org/10.1097/MNM.0000000000001014.

15. Buyse M, Thirion P, Carlson RW, Burzykowski T, Molenberghs G, Piedbois P. Relation between tumour response to first-line chemotherapy and survival in advanced colorectal cancer: a meta-analysis. Meta-Analysis Group in Cancer. Lancet (London, England). 2000;356(9227):373-8.

16. Therasse P, Arbuck SG, Eisenhauer EA, Wanders J, Kaplan RS, Rubinstein L, Verweij J, Van Glabbeke M, van Oosterom AT, Christian MC, Gwyther SG. New guidelines to evaluate the response to treatment in solid tumors. J Natl Cancer Inst. 2000;92(3):205-16. https://doi.org/10.1093/jnci/92.3.205.

17. Eisenhauer EA, Therasse $P$, Bogaerts J, Schwartz $L H$, Sargent D, Ford R, Dancey J, Arbuck S, Gwyther S, Mooney M, Rubinstein L, Shankar L, Dodd L, Kaplan R, Lacombe D, Verweij J. New response evaluation criteria in solid tumours: revised RECIST guideline (version 1.1). European journal of cancer (Oxford, England : 1990). 2009;45(2):228-47. https://doi.org/10.1016/j.ejca. 2008.10.026

18. Martin LK, Cucci A, Wei L, Rose J, Blazer M, Schmidt C, Khabiri H, Bloomston M, Bekaii-Saab T. Yttrium-90 radioembolization as salvage therapy for colorectal cancer with liver metastases. Clin Colorectal Cancer. 2012;11(3): 195-9. https://doi.org/10.1016/j.clcc.2011.12.002. 
19. Sofocleous CT, Violari EG, Sotirchos VS, Shady W, Gonen M, Pandit-Taskar N, Petre EN, Brody LA, Alago W, Do RK, D'Angelica MI, Osborne JR, Segal NH, Carrasquillo JA, Kemeny NE. Radioembolization as a salvage therapy for heavily pretreated patients with colorectal cancer liver metastases: factors that affect outcomes. Clin Colorectal Cancer. 2015;14(4):296-305. https://doi. org/10.1016/j.clcc.2015.06.003.

20. Bester L, Meteling B, Pocock N, Pavlakis N, Chua TC, Saxena A, Morris DL. Radioembolization versus standard care of hepatic metastases: comparative retrospective cohort study of survival outcomes and adverse events in salvage patients. Journal of vascular and interventional radiology : JVIR. 2012;23(1):96-105. https://doi.org/10.1016/j.jvir.2011.09.028.

21. Kennedy A, Cohn M, Coldwell DM, Drooz A, Ehrenwald E, Kaiser A, Nutting CW, Rose SC, Wang EA, Savin MA. Updated survival outcomes and analysis of long-term survivors from the MORE study on safety and efficacy of radioembolization in patients with unresectable colorectal cancer liver metastases. Journal of gastrointestinal oncology. 2017;8(4):614-24. https:// doi.org/10.21037/jgo.2017.03.10.

22. van den Hoven AF, Rosenbaum CE, Elias SG, de Jong HW, Koopman M, Verkooijen HM, Alavi A, van den Bosch MA, Lam MG. Insights into the doseresponse relationship of radioembolization with resin 90Y-microspheres: a prospective cohort study in patients with colorectal cancer liver metastases. Journal of nuclear medicine : official publication, Society of Nuclear Medicine. 2016;57(7):1014-9. https://doi.org/10.2967/jnumed.115.166942.

23. Salem R, Padia SA, Lam M, Bell J, Chiesa C, Fowers K, Hamilton B, Herman J, Kappadath SC, Leung T, Portelance L, Sze D, Garin E. Clinical and dosimetric considerations for Y90: recommendations from an international multidisciplinary working group. Eur J Nucl Med Mol Imaging. 2019;46(8): 1695-704. https://doi.org/10.1007/s00259-019-04340-5.

24. Kurilova I, Beets-Tan RGH, Flynn J, Gonen M, Ulaner G, Petre EN, Edward Boas F, Ziv E, Yarmohammadi H, Klompenhouwer EG, Cercek A, Kemeny NA, Sofocleous $C T$. Factors affecting oncologic outcomes of $90 Y$ radioembolization of heavily pre-treated patients with colon cancer liver metastases. Clin Colorectal Cancer. 2019;18(1):8-18. https://doi.org/10.1016/j. clcc.2018.08.004

25. Lahti SJ, Xing M, Zhang D, Lee JJ, Magnetta MJ, Kim HS. KRAS status as an independent prognostic factor for survival after yttrium-90 radioembolization therapy for unresectable colorectal cancer liver metastases. Journal of vascular and interventional radiology : JVIR. 2015; 26(8):1102-11. https://doi.org/10.1016/j.jvir.2015.05.032.

26. Prince JF, van den Bosch M, Nijsen JFW, Smits MLJ, van den Hoven AF, Nikolakopoulos S, Wessels FJ, Bruijnen RCG, Braat M, Zonnenberg BA, Lam M. Efficacy of radioembolization with holmium-166 microspheres in salvage patients with liver metastases: a phase 2 study. Journal of nuclear medicine : official publication, Society of Nuclear Medicine. 2017. https://doi.org/10. 2967/jnumed.117.197194

27. Kosmider S, Tan TH, Yip D, Dowling R, Lichtenstein M, Gibbs P. Radioembolization in combination with systemic chemotherapy as first-line therapy for liver metastases from colorectal cancer. Journal of vascular and interventional radiology : JVIR. 2011;22(6):780-6. https://doi.org/10.1016/j.jvir. 2011.02.023.

28. Ahmadzadehfar H, Sabet A, Meyer C, Habibi E, Biersack HJ, Ezziddin S. The importance of TC-MAA SPECT/CT for therapy planning of radioembolization in a patient treated with bevacizumab. Clin Nucl Med. 2012;37:1129-30.

29. Lam MG, Banerjee S, Louie JD, Abdelmaksoud MH, lagaru AH, Ennen RE, Sze DY. Root cause analysis of gastroduodenal ulceration after yttrium-90 radioembolization. Cardiovasc Interv Radiol. 2013;36(6):1536-47. https://doi. org/10.1007/s00270-013-0579-1.

30. Bhooshan N, Sharma NK, Badiyan S, Kaiser A, Moeslein FM, Kwok Y, Amin PP, Kudryasheva S, Chuong MD. Pretreatment tumor volume as a prognostic factor in metastatic colorectal cancer treated with selective internal radiation to the liver using yttrium-90 resin microspheres. Journal of gastrointestinal oncology. 2016;7(6):931-7. https://doi.org/10. 21037/jgo.2016.06.15.

31. Jakobs TF, Paprottka K, Raessler F, Strobl F, Lehner S, Ilhan H, Trumm CG, Fendler WP, Sommer W, Paprottka PM. Robust evidence for long-term survival with (90)Y radioembolization in chemorefractory liver-predominant metastatic colorectal cancer. Eur Radiol. 2017;27(1):113-9. https://doi.org/10. 1007/s00330-016-4345-z.

32. Sato K, Lewandowski R, Mulcahy MF, Atassi B, Ryu RK, Gates VL, Nemcek AA Jr, Barakat O, Benson AB 3rd, Mandal R, Talamonti M, Wong CY, Miller FH, Newman S, Shaw JM, Thurston K, Omary RA, Salem R. Unresectable chemorefractory liver metastases: radioembolization with $90 \mathrm{Y}$ microspheres - safety, efficacy, and survival. Radiology. 2008;247(2):507-15.

33. Abbott AM, Kim R, Hoffe SE, Arslan B, Biebel B, Choi J, El-Haddad G, Kis B, Sweeney J, Meredith KL, Almhanna K, Strosberg J, Shibata D, Fulp WJ, Shridhar R. Outcomes of therasphere radioembolization for colorectal metastases. Clin Colorectal Cancer. 2015;14(3):146-53. https://doi.org/10. 1016/j.clcc.2015.02.002

34. Salem R, Thurston KG. Radioembolization with 90Yttrium microspheres: a state-of-the-art brachytherapy treatment for primary and secondary liver malignancies. Part 1: Technical and methodologic considerations. Journal of vascular and interventional radiology : JVIR. 2006;17(8):1251-78. https://doi. org/10.1097/01.RVI.0000233785.75257.9A.

35. Salem R, Thurston KG. Radioembolization with 90yttrium microspheres: a state-of-the-art brachytherapy treatment for primary and secondary liver malignancies. Part 2: special topics. Journal of vascular and interventional radiology : JVIR. 2006;17(9):1425-39. https://doi.org/10.1097/01.RVI. 0000235779.88652 .53 .

36. Salem R, Thurston KG. Radioembolization with yttrium-90 microspheres: a state-of-the-art brachytherapy treatment for primary and secondary liver malignancies: part 3: comprehensive literature review and future direction. Journal of vascular and interventional radiology : JVIR. 2006;17(10):1571-93. https://doi.org/10.1097/01.RVI.0000236744.34720.73.

37. Smits MLJ, Nijsen JFW, van den Bosch MAAJ, Lam MGEH, Vente MAD, Mali WPTM, van het Schip AD, Zonnenberg BA. Holmium-166 radioembolisation in patients with unresectable, chemorefractory liver metastases (HEPAR trial): a phase 1, dose-escalation study. The Lancet Oncology. 2012;13(10):102534. https://doi.org/10.1016/s1470-2045(12)70334-0.

38. Firth D. Bias reduction of maximum likelihood estimates. Biometrika. 1993; 89(1):27-38.

39. Seidensticker $R$, Denecke T, Kraus P, Seidensticker M, Mohnike K, Fahlke J, Kettner E, Hildebrandt B, Dudeck O, Pech M, Amthauer H, Ricke J. Matchedpair comparison of radioembolization plus best supportive care versus best supportive care alone for chemotherapy refractory liver-dominant colorectal metastases. Cardiovasc Interv Radiol. 2012;35(5):1066-73. https://doi.org/10. 1007/s00270-011-0234-7.

40. Kennedy AS, Ball DS, Cohen SJ, Cohn M, Coldwell DM, Drooz A, Ehrenwald E, Kanani S, Nutting CW, Moeslein FM, Putnam SG 3rd, Rose SC, Savin MA, Schirm S, Sharma NK, Wang EA. Hepatic imaging response to radioembolization with yttrium-90-labeled resin microspheres for tumor progression during systemic chemotherapy in patients with colorectal liver metastases. Journal of gastrointestinal oncology. 2015;6(6):594-604. https:// doi.org/10.3978/j.issn.2078-6891.2015.082.

41. Lewandowski RJ, Memon K, Mulcahy MF, Hickey R, Marshall K, Williams M, Salzig K, Gates VL, Atassi B, Vouche M, Atassi R, Desai K, Hohlastos E, Sato K, Habib A, Kircher S, Newman SB, Nimeiri H, Benson AB, Salem R. Twelve-year experience of radioembolization for colorectal hepatic metastases in 214 patients: survival by era and chemotherapy. Eur J Nucl Med Mol Imaging. 2014;41(10):1861-9. https://doi.org/10.1007/s00259-014-2799-2.

42. Shady W, Petre EN, Gonen M, Erinjeri JP, Brown KT, Covey AM, Alago W, Durack JC, Maybody M, Brody LA, Siegelbaum RH, D'Angelica MI, Jarnagin WR, Solomon SB, Kemeny NE, Sofocleous CT. Percutaneous radiofrequency ablation of colorectal cancer liver metastases: factors affecting outcomes--a 10-year experience at a single center. Radiology. 2016;278(2):601-11. https:// doi.org/10.1148/radiol.2015142489.

43. Shady W, Sotirchos VS, Do RK, Pandit-Taskar N, Carrasquillo JA, Gonen M, Sofocleous CT. Surrogate imaging biomarkers of response of colorectal liver metastases after salvage radioembolization using 90Y-loaded resin microspheres. AJR Am J Roentgenol. 2016;207(3):661-70. https://doi.org/10. 2214/ajr.15.15202.

44. Seidensticker R, Damm R, Enge J, Seidensticker M, Mohnike K, Pech M, Hass P, Amthauer H, Ricke J. Local ablation or radioembolization of colorectal cancer metastases: comorbidities or older age do not affect overall survival. BMC Cancer. 2018;18(1):882. https://doi.org/10.1186/s12885-018-4784-9.

45. Rosenbaum CE, van den Hoven AF, Braat MN, Koopman M, Lam MG, Zonnenberg BA, Verkooijen HM, van den Bosch MA. Yttrium-90 radioembolization for colorectal cancer liver metastases: a prospective cohort study on circulating angiogenic factors and treatment response. EJNMMI Res. 2016;6(1):92. https://doi.org/10.1186/s13550-016-0236-1.

46. Tohme S, Sukato D, Nace GW, Zajko A, Amesur N, Orons P, Chalhoub D, Marsh JW, Geller DA, Tsung A. Survival and tolerability of liver radioembolization: a comparison of elderly and younger patients with 
metastatic colorectal cancer. HPB : the official journal of the International Hepato Pancreato Biliary Association. 2014;16(12):1110-6. https://doi.org/10. 1111/hpb.12307.

47. Soydal C, Kucuk NO, Balci D, Gecim E, Bilgic S, Elhan AH. Prognostic importance of the presence of early metabolic response and absence of extrahepatic metastasis after selective internal radiation therapy in colorectal cancer liver metastasis. Cancer Biother Radiopharm. 2016;31(9): 342-6. https://doi.org/10.1089/cbr.2016.2105.

48. Paprottka KJ, Schoeppe F, Ingrisch M, Rubenthaler J, Sommer NN, De Toni E, Ilhan H, Zacherl M, Todica A, Paprottka PM. Pre-therapeutic factors for predicting survival after radioembolization: a single-center experience in 389 patients. Eur J Nucl Med Mol Imaging. 2017;44(7):1185-93. https://doi.org/ 10.1007/s00259-017-3646-z.

49. Mulcahy MF, Lewandowski RJ, Ibrahim SM, Sato KT, Ryu RK, Atassi B, Newman S, Talamonti M, Omary RA, Benson A 3rd, Salem R. Radioembolization of colorectal hepatic metastases using yttrium-90 microspheres. Cancer. 2009;115(9):1849-58. https://doi.org/10.1002/ cncr.24224.

50. Gibbs P, Heinemann V, Sharma NK, Taieb J, Ricke J, Peeters M, Findlay M, Robinson B, Jackson C, Strickland A, Gebski V, Van Buskirk M, Zhao H, van Hazel G. Effect of primary tumor side on survival outcomes in untreated patients with metastatic colorectal cancer when selective internal radiation therapy is added to chemotherapy: combined analysis of two randomized controlled studies. Clin Colorectal Cancer. 2018;17(4):e617-29. https://doi. org/10.1016/j.clcc.2018.06.001.

51. Duffy MJ. Carcinoembryonic antigen as a marker for colorectal cancer: is it clinically useful? Clin Chem. 2001;47(4):624-30.

52. Ziv E, Bergen M, Yarmohammadi H, Boas FE, Petre EN, Sofocleous $C T$, Yaeger R, Solit DB, Solomon SB, Erinjeri JP. PI3K pathway mutations are associated with longer time to local progression after radioembolization of colorectal liver metastases. Oncotarget. 2017;8(14):23529-38.

53. Frankema-Mourer JS, Heymans J (2016) Standpunt Yttrium-90 radioembolisatie bij colorectale levermetastasen Zorginstituut Nederland.

54. Virdee PS, Moschandreas J, Gebski V, Love SB, Francis EA, Wasan HS, van Hazel G, Gibbs P, Sharma RA. Protocol for combined analysis of FOXFIRE, SIRFLOX, and FOXFIRE-Global randomized phase III trials of chemotherapy + - selective internal radiation therapy as first-line treatment for patients with metastatic colorectal cancer. JMIR research protocols. 2017;6(3):e43. https://doi.org/10.2196/resprot.7201.

55. Wasan HS, Gibbs P, Sharma NK, Taieb J, Heinemann V, Ricke J, Peeters M, Findlay M, Weaver A, Mills J, Wilson C, Adams R, Francis A, Moschandreas J, Virdee PS, Dutton P, Love S, Gebski V, Gray A, van Hazel G, Sharma RA. Firstline selective internal radiotherapy plus chemotherapy versus chemotherapy alone in patients with liver metastases from colorectal cancer (FOXFIRE, SIRFLOX, and FOXFIRE-Global): a combined analysis of three multicentre, randomised, phase 3 trials. The Lancet Oncology. 2017; 18(9):1159-71. https://doi.org/10.1016/s1470-2045(17)30457-6.

56. Ulrich G, Dudeck O, Furth C, Ruf J, Grosser OS, Adolf D, Stiebler M, Ricke J, Amthauer $\mathrm{H}$. Predictive value of intratumoral $99 \mathrm{mTc}$-macroaggregated albumin uptake in patients with colorectal liver metastases scheduled for radioembolization with $90 \mathrm{Y}$-microspheres. Journal of nuclear medicine : official publication, Society of Nuclear Medicine. 2013;54(4):516-22. https:// doi.org/10.2967/jnumed.112.112508.

57. Jongen JMJ, Rosenbaum C, Braat M, van den Bosch M, Sze DY, Kranenburg O, Borel Rinkes IHM, Lam M, van den Hoven AF. Anatomic versus metabolic tumor response assessment after radioembolization treatment. Journal of vascular and interventional radiology : JVIR. 2018;29(2):244-53 e242. https:// doi.org/10.1016/j.jvir.2017.09.024.

58. Hendlisz A, Van den Eynde M, Peeters M, Maleux G, Lambert B, Vannoote J, De Keukeleire K, Verslype C, Defreyne L, Van Cutsem E, Delatte P, Delaunoit T, Personeni N, Paesmans M, Van Laethem JL, Flamen P. Phase III trial comparing protracted intravenous fluorouracil infusion alone or with yttrium-90 resin microspheres radioembolization for liver-limited metastatic colorectal cancer refractory to standard chemotherapy. Journal of clinical oncology : official journal of the American Society of Clinical Oncology. 2010;28(23):3687-94. https://doi.org/10.1200/JCO.2010.28.5643.

59. Braat AJAT, Kappadath SC, Bruijnen RC, Van den Hoven AF, Mahvash A, De Jong HW, Lam MGEH. Adequate SIRT activity dose is as important as adequate chemotherapy dose. Lancet Oncol. 2017;18:e636.

60. Lam MG, Louie JD, Abdelmaksoud MH, Fisher GA, Cho-Phan CD, Sze DY Limitations of body surface area-based activity calculation for radioembolization of hepatic metastases in colorectal cancer. Journal of vascular and interventional radiology : JVIR. 2014;25(7):1085-93. https://doi. org/10.1016/j.jvir.2013.11.018.

61. Garin E, Tzelikas L, Guiu B, Chalaye J, Edeline J, Baere TD, Tacher V, Robert C, Assenat E, Terroir-Cassou-Mounat M, Regnault H, Palard X, Laffont S, Campillo-Gimenez B, Rolland Y (2020) Major impact of personalized dosimetry using $90 \mathrm{Y}$ loaded glass microspheres SIRT in HCC: Final overall survival analysis of a multicenter randomized phase II study (DOSISPHERE01). J Clin Oncol 38 (4_suppl):516-516. doi:https://doi.org/10.1200/JCO.2020. 38.4_suppl.516.

62. van Roekel C, Bastiaannet R, Smits ML, Bruijnen RC, Braat A, de Jong $H$, Elias SG, Lam M. Dose-effect relationships of holmium-166 radioembolization in colorectal cancer. Journal of nuclear medicine : official publication, Society of Nuclear Medicine. 2020. https://doi.org/10.2967/ jnumed.120.243832.

63. Zerizer I, Al-Nahhas A, Towey D, Tait P, Ariff B, Wasan H, Hatice G, Habib N, Barwick T. The role of early (1)(8)F-FDG PET/CT in prediction of progressionfree survival after (9)(0)Y radioembolization: comparison with RECIST and tumour density criteria. Eur J Nucl Med Mol Imaging. 2012;39(9):1391-9. https://doi.org/10.1007/s00259-012-2149-1.

64. Finessi M, Bellò M, Giunta FP, Veltri A, Deandreis D. Interventional locoregional treatment and metabolic response: advantages of using PET/ CT in the evaluation of response to treatment. Quarterly Journal of Nuclear Medicine and Molecular Imaging. 2018:62(2):165-84.

65. Shady W, Kishore S, Gavane S, Do RK, Osborne JR, Ulaner GA, Gonen M, Ziv E, Boas FE, Sofocleous CT. Metabolic tumor volume and total lesion glycolysis on FDG-PET/CT can predict overall survival after (90)Y radioembolization of colorectal liver metastases: a comparison with SUVmax, SUVpeak, and RECIST 1.0. Eur J Radiol. 2016;85(6):1224-31. https:// doi.org/10.1016/j.ejrad.2016.03.029.

66. Rosenbaum CE, van den Bosch MA, Veldhuis WB, Huijbregts JE, Koopman M, Lam MG. Added value of FDG-PET imaging in the diagnostic workup for yttrium-90 radioembolisation in patients with colorectal cancer liver metastases. Eur Radiol. 2013;23(4):931-7. https:// doi.org/10.1007/s00330-012-2693-x.

\section{Publisher's Note}

Springer Nature remains neutral with regard to jurisdictional claims in published maps and institutional affiliations.

\section{Submit your manuscript to a SpringerOpen ${ }^{\circ}$ journal and benefit from:}

- Convenient online submission

Rigorous peer review

- Open access: articles freely available online

- High visibility within the field

- Retaining the copyright to your article

Submit your next manuscript at $>$ springeropen.com 